\title{
Comment on "Biomarkers as Potential Treatment Targets in Inflammatory Bowel Disease: A Systematic Review"
}

\author{
Nicholas-Paul Delicata, Neville Azzopardi, and Pierre Ellul \\ Department of Gastroenterology, Mater Dei Hospital, Msida MSD 2090, Malta \\ Correspondence should be addressed to Neville Azzopardi; neville.azzopardi@gov.mt
}

Received 2 December 2015; Accepted 23 December 2015

Copyright (C) 2016 Nicholas-Paul Delicata et al. This is an open access article distributed under the Creative Commons Attribution License, which permits unrestricted use, distribution, and reproduction in any medium, provided the original work is properly cited.

We read with interest the article entitled "Biomarkers as Potential Treatment Targets in Inflammatory Bowel Disease: A Systemic Review," which brings forward evidence that serum and faecal biomarkers do not possess adequate operational characteristics to make them stand-alone treatment targets in inflammatory bowel disease (IBD) but should be considered as important adjunctive measures to clinical, endoscopic, and radiographic assessment [1].

We recently carried out a study at Mater Dei Hospital, Malta, where we compared the positive predictive value of faecal calprotectin (FC) in patients with newly diagnosed inflammatory bowel disease (IBD), compared to the more widely used erythrocyte sedimentation rate (ESR) and Creactive protein (CRP). Our patient population consisted of 97 patients with a histological diagnosis of IBD and in whom all three biomarkers (FC, ESR, and CRP) were taken. All faecal calprotectin values were positive (with a mean average of $807 \mathrm{mg} / \mathrm{L}$; normal < $50 \mathrm{mg} / \mathrm{L}$ ). ESR was only elevated in $45 \%$ of cases while CRP was elevated in only $21 \%$ of cases. From the 97 patients; 60 were diagnosed with Crohn's disease (CD), 34 with ulcerative colitis (UC), and 3 with indeterminate IBD.

The mean FC level, ESR, and CRP were $857 \mathrm{mg} / \mathrm{L}$, $37 \mathrm{~mm} / \mathrm{hr}$, and $30 \mathrm{mg} / \mathrm{L}$ in $\mathrm{CD} ; 771 \mathrm{mg} / \mathrm{L}, 39 \mathrm{~mm} / \mathrm{hr}$, and $62 \mathrm{mg} / \mathrm{L}$ in UC; $180 \mathrm{mg} / \mathrm{L}, 40 \mathrm{~mm} / \mathrm{hr}$, and $23 \mathrm{mg} / \mathrm{L}$ in indeterminate IBD.

There was no statistical significance between the adult and paediatric populations. These results demonstrate and confirm that ESR and CRP are poor markers of intestinal inflammation, when compared to faecal calprotectin. This data suggests that all IBD patients should have a faecal calprotectin measured at outpatients rather than ESR and CRP in order to assess clinical activity even in the absence of gastrointestinal symptoms.

The role of FC in the investigation and management of gastrointestinal pathologies has been on the increase. Nowadays faecal calprotectin is playing a major role in the investigation and diagnosis of patients presenting to the physician with lower gastrointestinal symptoms. When taken appropriately a negative faecal calprotectin would rule out IBD thus sparing most people with irritable bowel syndrome from having costly and invasive investigations [2].

Faecal calprotectin has been demonstrated to correlate better with endoscopic disease activity than clinical activity, CRP, platelets, haemoglobin, and blood leukocytes. Furthermore, the strong correlation of faecal calprotectin with endoscopic disease activity suggested that calprotectin is indeed a useful biomarker for the noninvasive monitoring of disease activity in patients [3]. FC is also useful in predicting the probability of relapses in both quiescent ulcerative colitis and quiescent Crohn's disease [4, 5].

Thus in the context of the ever-increasing financial burden on the health services and the better performance of FC as a biomarker, ESR and CRP should only be requested in exceptional circumstances.

\section{Conflict of Interests}

There is no conflict of interests related to this paper. 


\section{References}

[1] T. B. Murdoch, S. O’Donnell, M. S. Silverberg, and R. Panaccione, "Biomarkers as potential treatment targets in inflammatory bowel disease: a systematic review," Canadian Journal of Gastroenterology and Hepatology, vol. 29, no. 4, pp. 203-208, 2015.

[2] L. A. Smith and D. R. Gaya, "Utility of faecal calprotectin analysis in adult inflammatory bowel disease," World Journal of Gastroenterology, vol. 18, no. 46, pp. 6782-6789, 2012.

[3] A. M. Schoepfer, C. Beglinger, A. Straumann et al., "Fecal calprotectin more accurately reflects endoscopic activity of ulcerative colitis than the lichtiger index, C-reactive protein, platelets, hemoglobin, and blood leukocytes," Inflammatory Bowel Diseases, vol. 19, no. 2, pp. 332-341, 2013.

[4] T. Yamamoto, M. Shiraki, T. Bamba, S. Umegae, and K. Matsumoto, "Fecal calprotectin and lactoferrin as predictors of relapse in patients with quiescent ulcerative colitis during maintenance therapy," International Journal of Colorectal Disease, vol. 29, no. 4, pp. 485-491, 2014.

[5] G. D. Naismith, L. A. Smith, S. J. E. Barry et al., "A prospective evaluation of the predictive value of faecal calprotectin in quiescent Crohn's disease," Journal of Crohn's and Colitis, vol. 8, no. 9, pp. 1022-1029, 2014. 


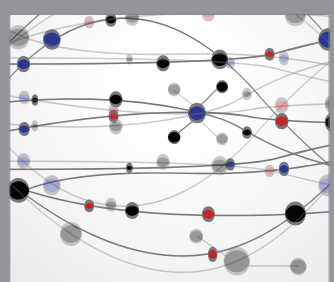

The Scientific World Journal
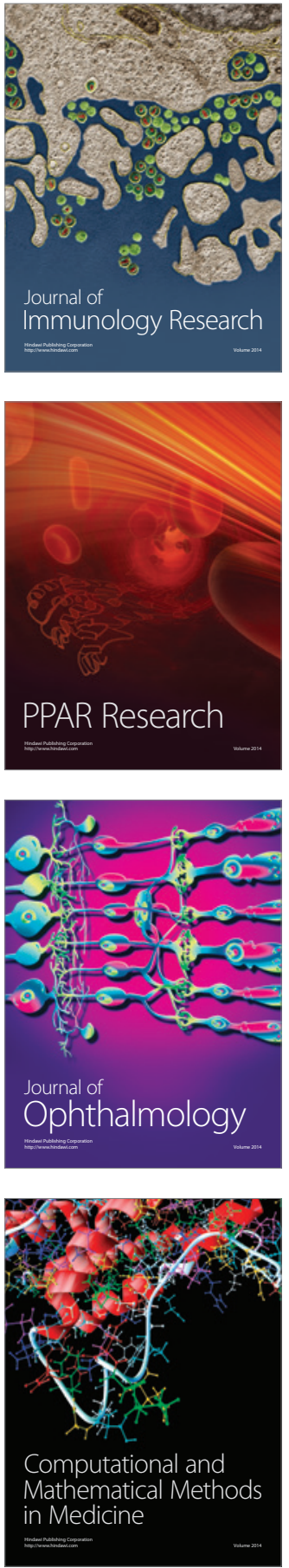

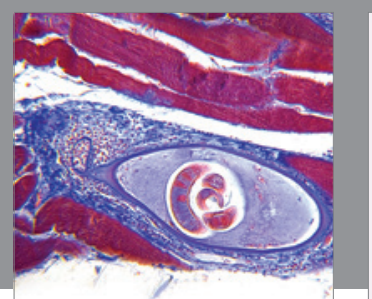

Gastroenterology Research and Practice

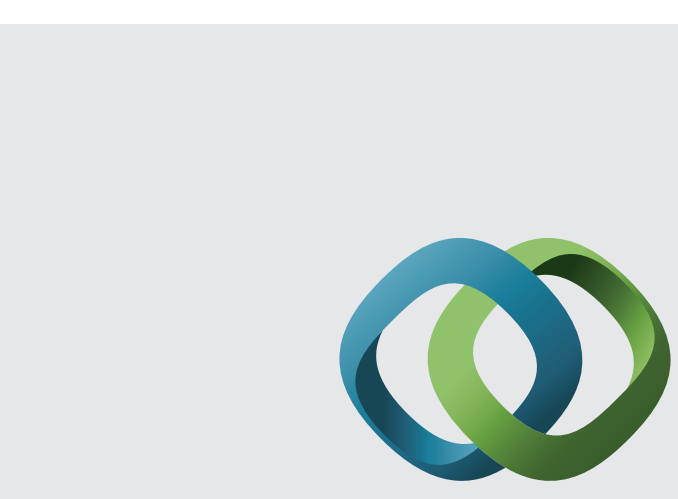

\section{Hindawi}

Submit your manuscripts at

http://www.hindawi.com
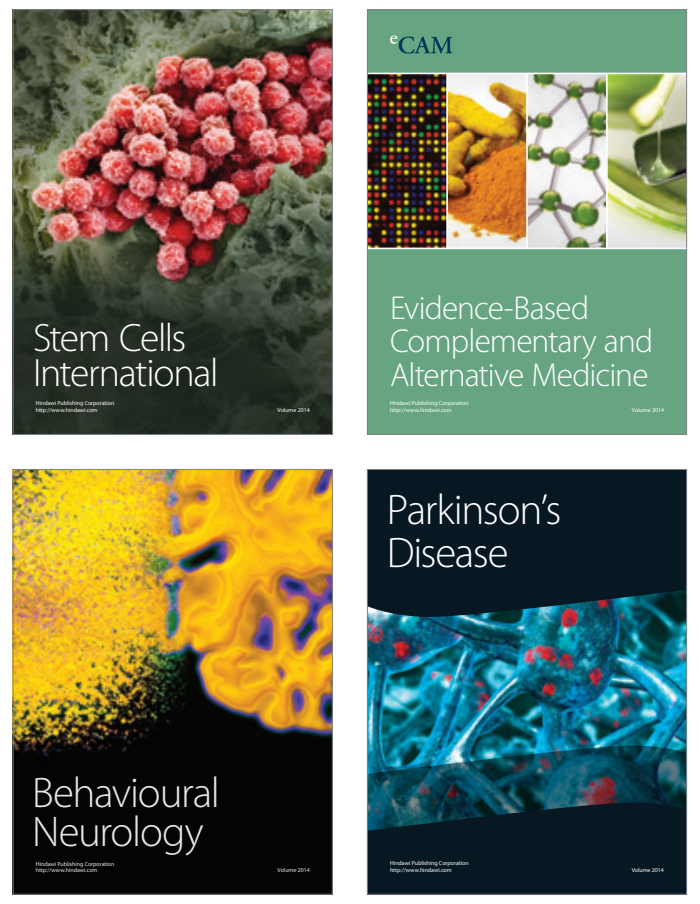
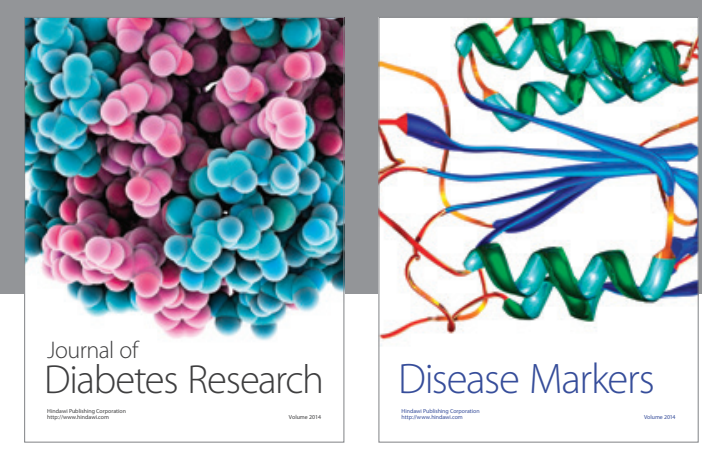

Disease Markers
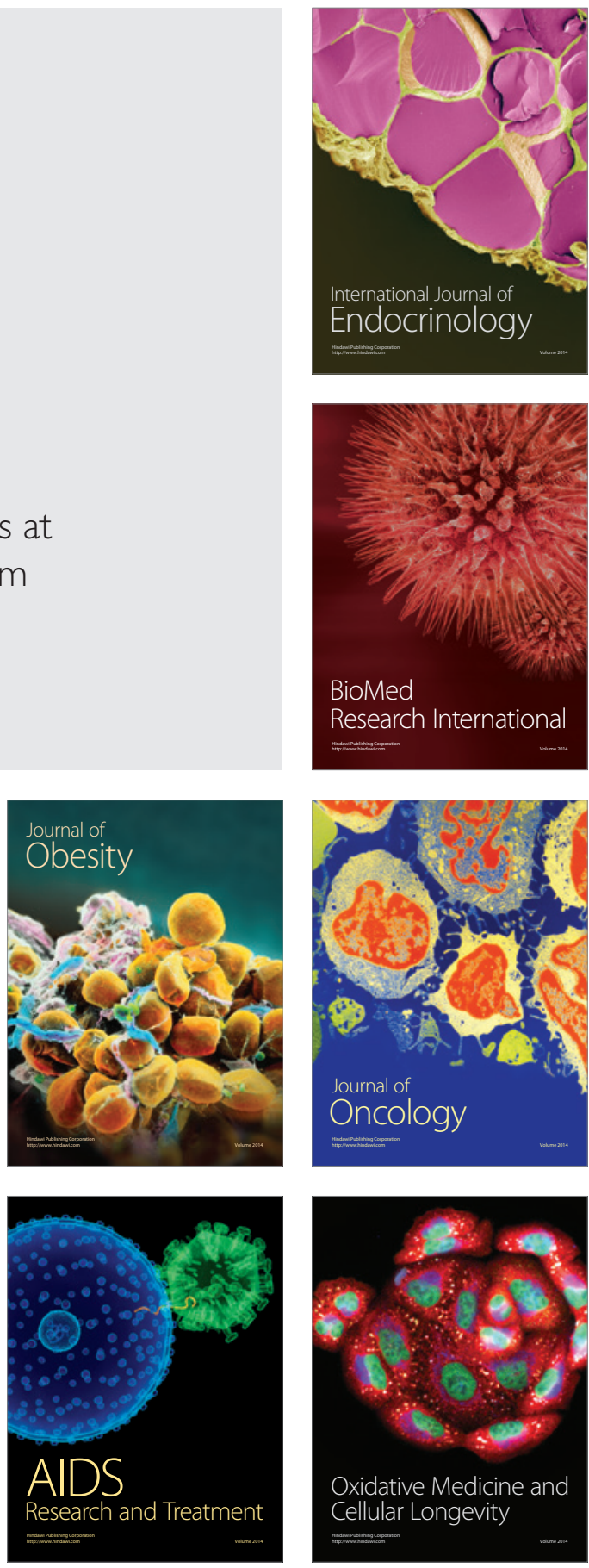